ORNL/SUb--89-SD841/3

DE91 000520

\title{
REQUIREMENTS FOR CANISTERS USED FOR DELIVERY OF SPENT NUCLEAR FUEL AND ASSOCIATED MATERIALS TO DOE UNDER STANDARD DISPOSAL CONTRACTS
}

Date Published - June 1990

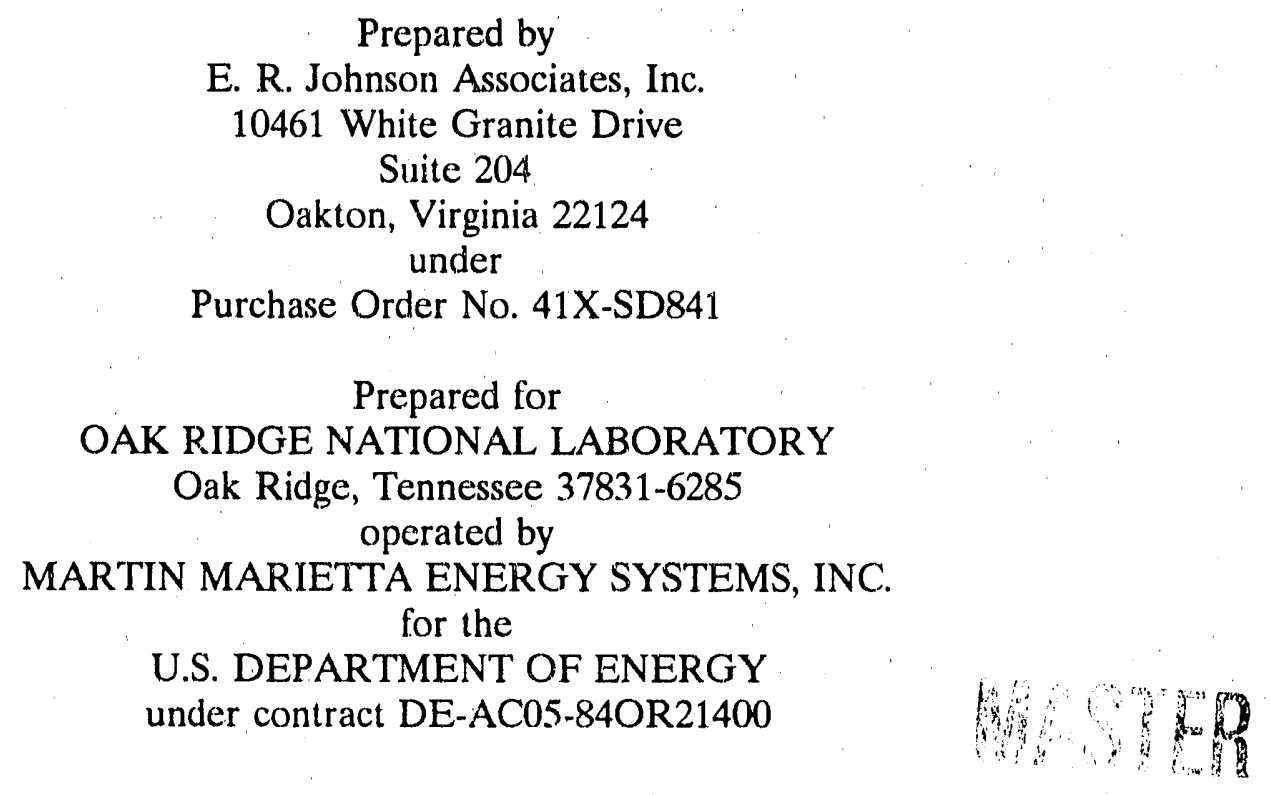




\section{FOREWORD}

This report is one of a series of eight prepared by E. R. Johnson Associates, Inc. (JAI) under ORNL's contract with DOE's OCRWM Systems Integration Program and in support of the Annual Capacity Report (ACR) Issue Resolution Process. The report topics relate specifically to the list of high priority technical waste acceptance issues developed jointly by DOE and a utility-working group. JAI performed various analyses and studies on each topic to serve as starting points for further discussion and analysis leading eventually to finalizing the process by which DOE will accept spent fuel and waste into its waste management system. The eight reports are concerned with the conditions under which spent fuel and high level waste will be accepted in the following categories:

1. Failed Fuel

2. Consolidated Fuel and Associated Structural Parts

3. Non-Fuel-Assembly Hardware

4. Fuel in Metal Storage Casks

5. Fuel in Multi-Element Sealed Canisters

6. Inspection and Testing Requirements for Wastes

7. Canister Criteria

8. Spent Fuel Selection for Delivery

9. Defense and Commercial High-Level Waste Packages

As a part of the report preparation, each was subjected to a rigorous peer review by a group of knowledgeable and independent experts. These reports have not yet been formally reviewed by DOE and, therefore, do not represent DOE policy. 
REQUIREMENTS FOR CANISTERS USED FOR DELIVERY OF SPENT NUCLEAR FUEL AND ASSOCIATED MATERIALS TD DOE UNDER STANDARD DISPOSAL CONTRACTS

The Department of Energy (DOE) is studying prospective changes to the waste acceptance criteria contained in the Standard Contract* which involve consideration of the possible acceptance of failed fuel, consolidated fuel rods, compacted structural parts resulting from atreactor consolidation operations, and other non-fuel bearing materials on the same scheduling basis as used for standard fuel ** under the existing Staridard Contract. During the course of these studies it has become clear that all such forms of spent fuel and related wastes would have to be delivered to DOE (and stored at the reactor) in a container having an envelope about the same as the fuel assemblies from which the fuel forms originated. Thus, the first objective of the DOE effort has been to develop draft requirements for canisters to be used by utilities (and others) to deliver the foregoing forms of spent fuel and related wastes. These draft requirements have been completed and are included in the attachment hereto.

Separate DOE contractor efforts are being directed toward establishing the conditions under which failed fuel, consolidated fuel rods, compacted structural parts resulting from reactor consolidation, and other non fuel assembly (NFA) hardware might be accepted by DOE, when packaged in a canister meeting the requirements set forth herein, on the same scheduling basis as used for intact non-defective fuel assemblies under the existing Standard contract. Such conditions may include limitations on the thermal output of the contents or the neutron and

\footnotetext{
*The Standard Contract between DOE and utilities (and others) for disposal of spent nuclear fuel and high level radioactive waste as set forth in 10CFR961.

**Standard fuel under the existing Standard Contract includes only intact and non-defective fuel assemblies which meet certain dimensionsal and thermal output limitations.
} 
gamma dose rate at the surface of the canister, the minimum amount of consolidated fuel contained in the canister, and the like. Thus, delivery of these fuel and waste forms to DOE in a canister meeting these requirements is a necessary but not sufficient condition to permit acceptance thereof on the same scheduling basis as for intact nondefective fuel assemblies.

In developing these canister requirements, it was recognized that DOE is obligated under existing disposal contracts to be able to handle intact fuel assemblies having a variety of handling fixtures, crosssectional dimensions, and lengths, and thus similar ranges of variations have been permitted in the requirements for the canisters that are used to deliver failed fuel, consolidated fuel rods, compacted structural parts resulting from at-reactor consolidation, and other NFA hardware. Moreover, it has been recognized that utilities should have the maximum flexibility to design canisters that meet their individual requirements and to take advantage of prospective canister design innovations. Therefore, these requirements have provided only those necessary to enable DOE to handle the canisters both safely and efficiently in its facilities. Thus, they represent functional performance requirements only with respect to envelope dimensions, handling features, materials of construction, capability of the canisters to withstand the normal loads to which they are expected to be subjected, prevention of stress corrosion cracking, draining, identification and tamper-safing, and particulate containment (as applicable). This is intended to leave wide discretion to the utilities in designing canisters that can be used to store spent fuel at the reactor to achieve minimum cost and take advantage of changes in state-of-the-art for canister design, without compromising the ability of DOE to meet applicable safety requirements and maintain operational efficiency in its facilities.

The draft requirements shown in the attachment represent the first step toward the possible broadening of the variety of spent fuel and waste forms described in the Standard Contract that might be accepted by DOE on the same scheduling basis as intact non-defective spent fuel assembilies. Designs of canisters other than those meeting these requirements would be expected to be considered for use by DOE on a case 
by case basis inasmuch as it is recognized that canister types other than those specified in the attachment may be acceptable for use in the DOE system.

The requirements for canisters to be used by utilities to deliver spent fuel and associated materials as described herein should not be confused with those that may be applicable for a common or universal canister; i.e., a canister that could be optimally used in both the utility and DOE spent fuel management systems. 


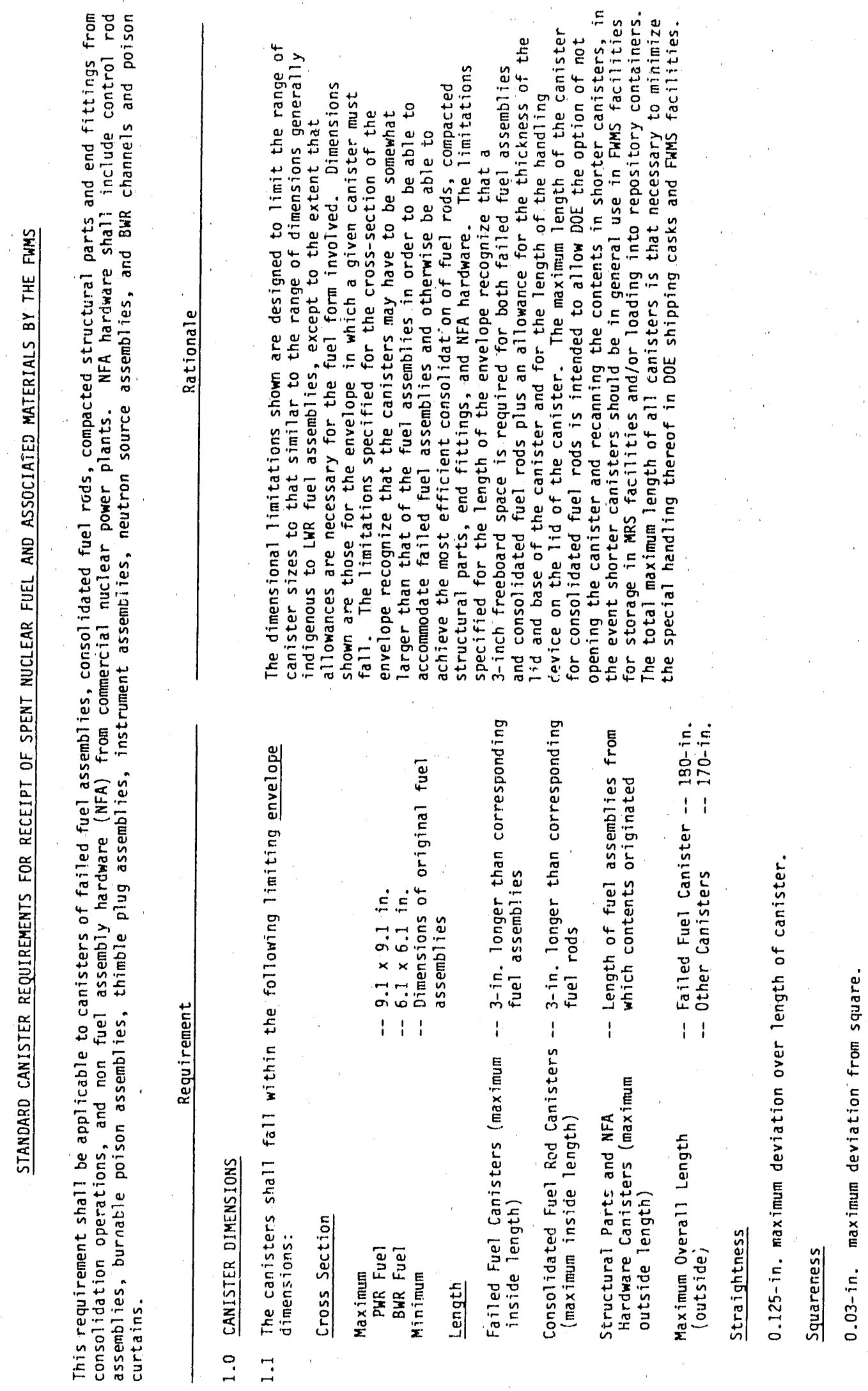



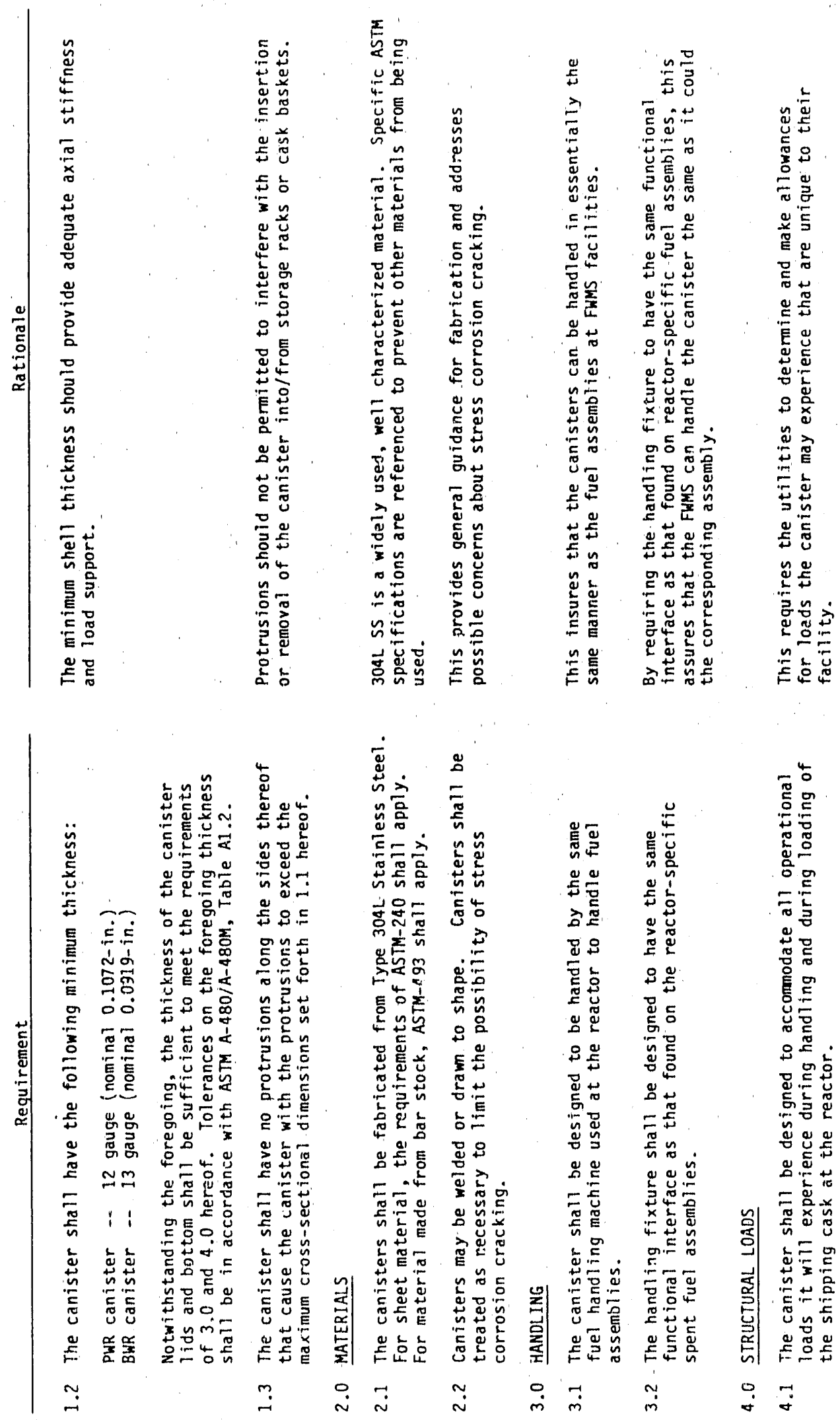


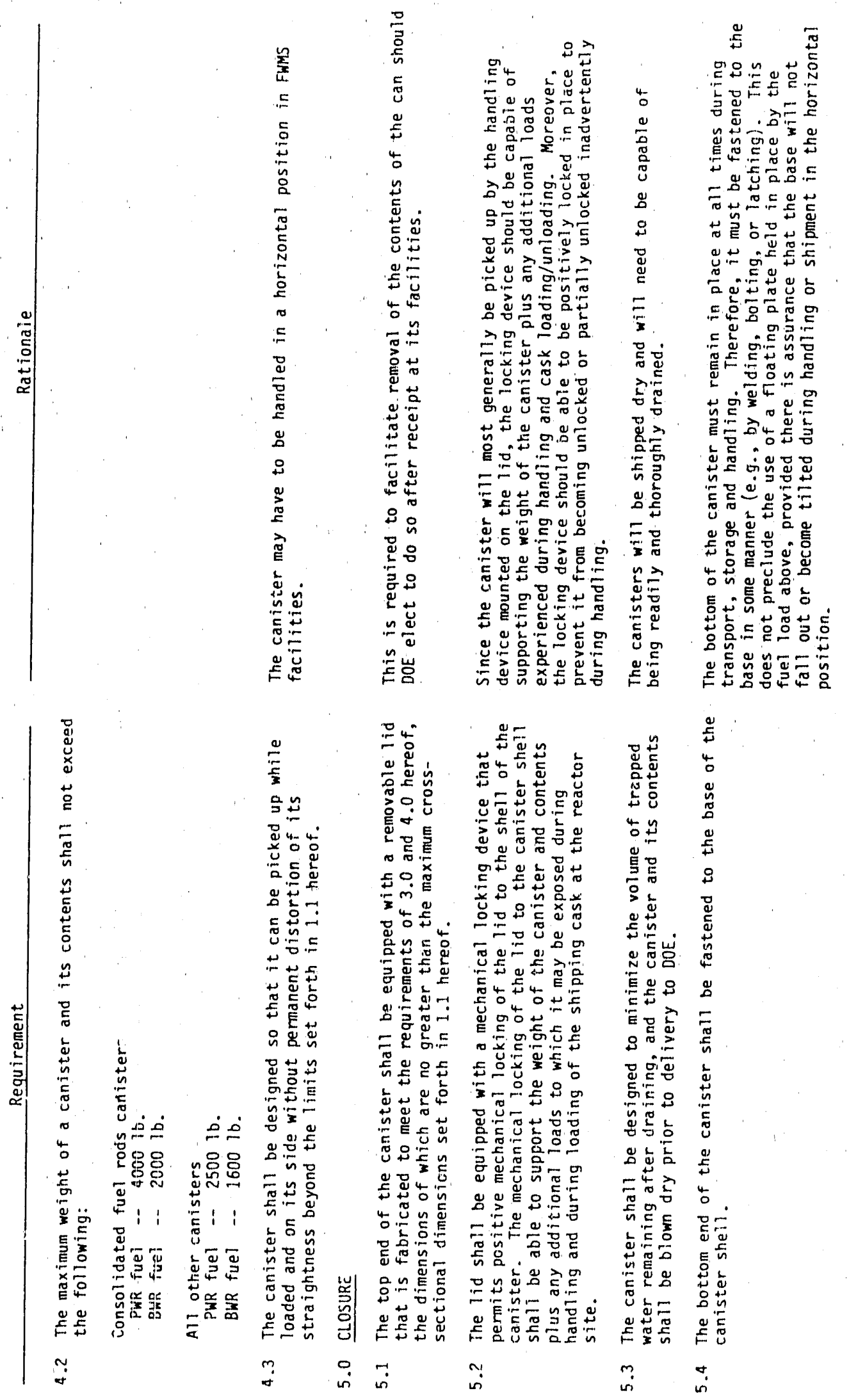




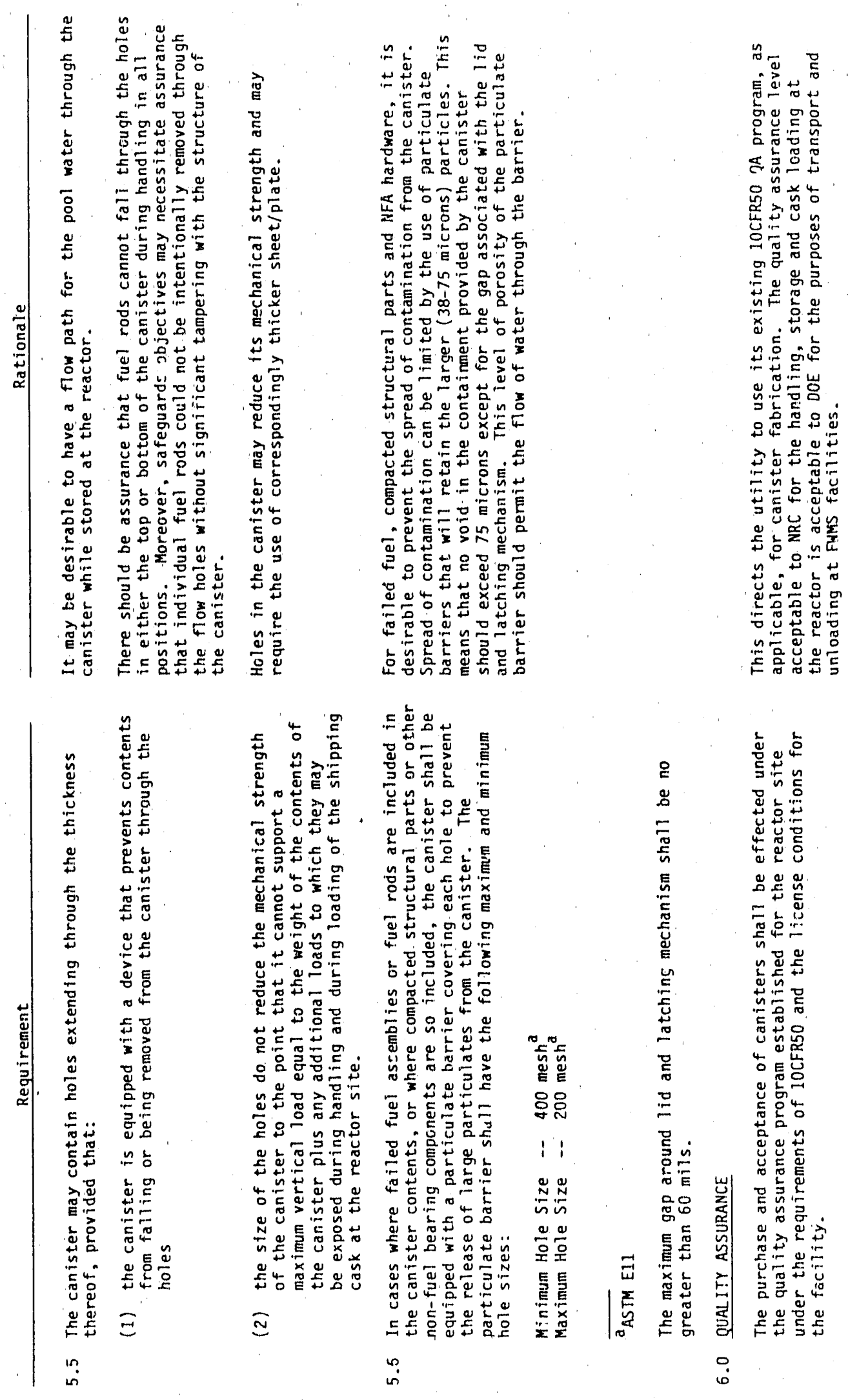



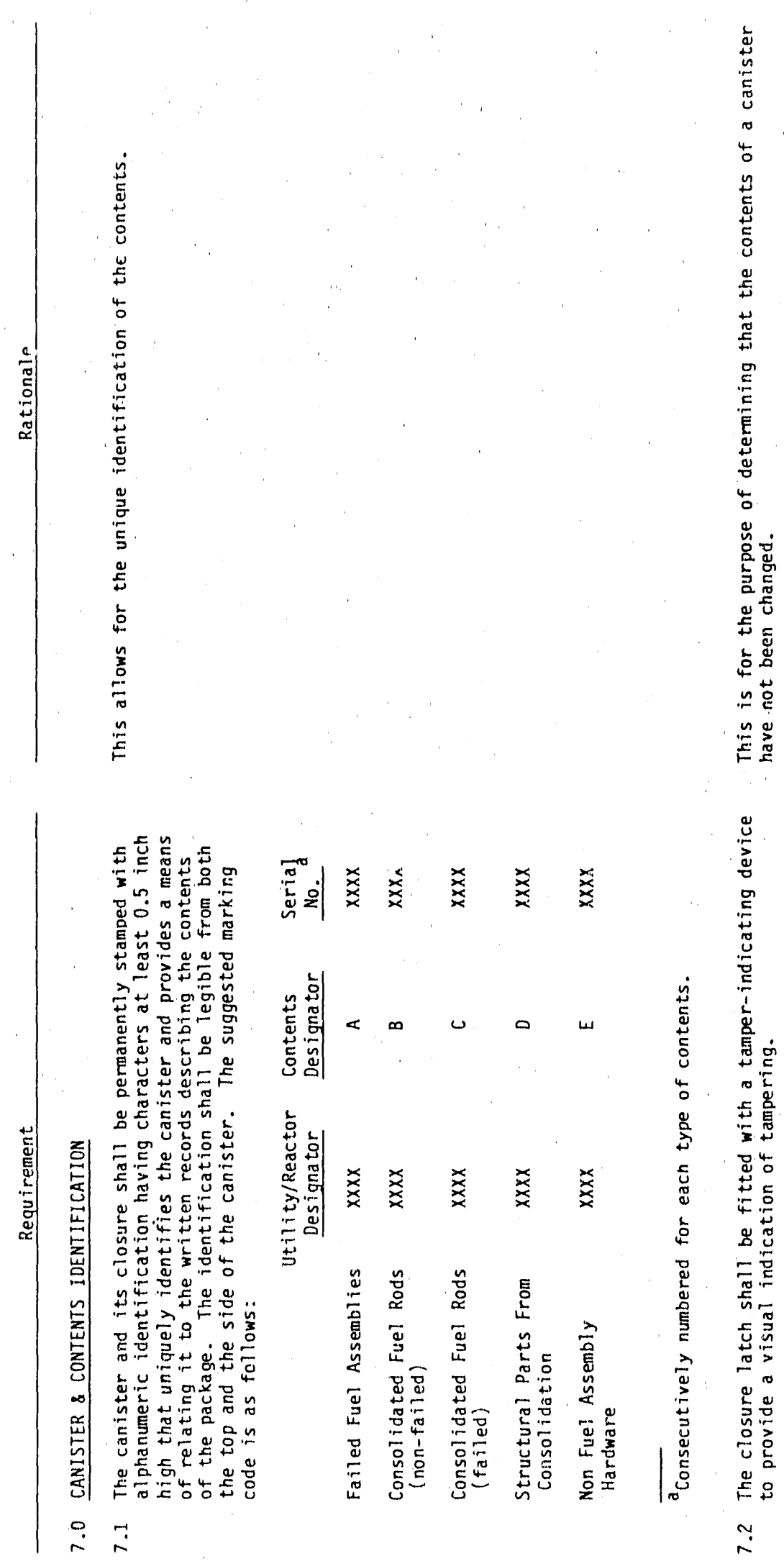

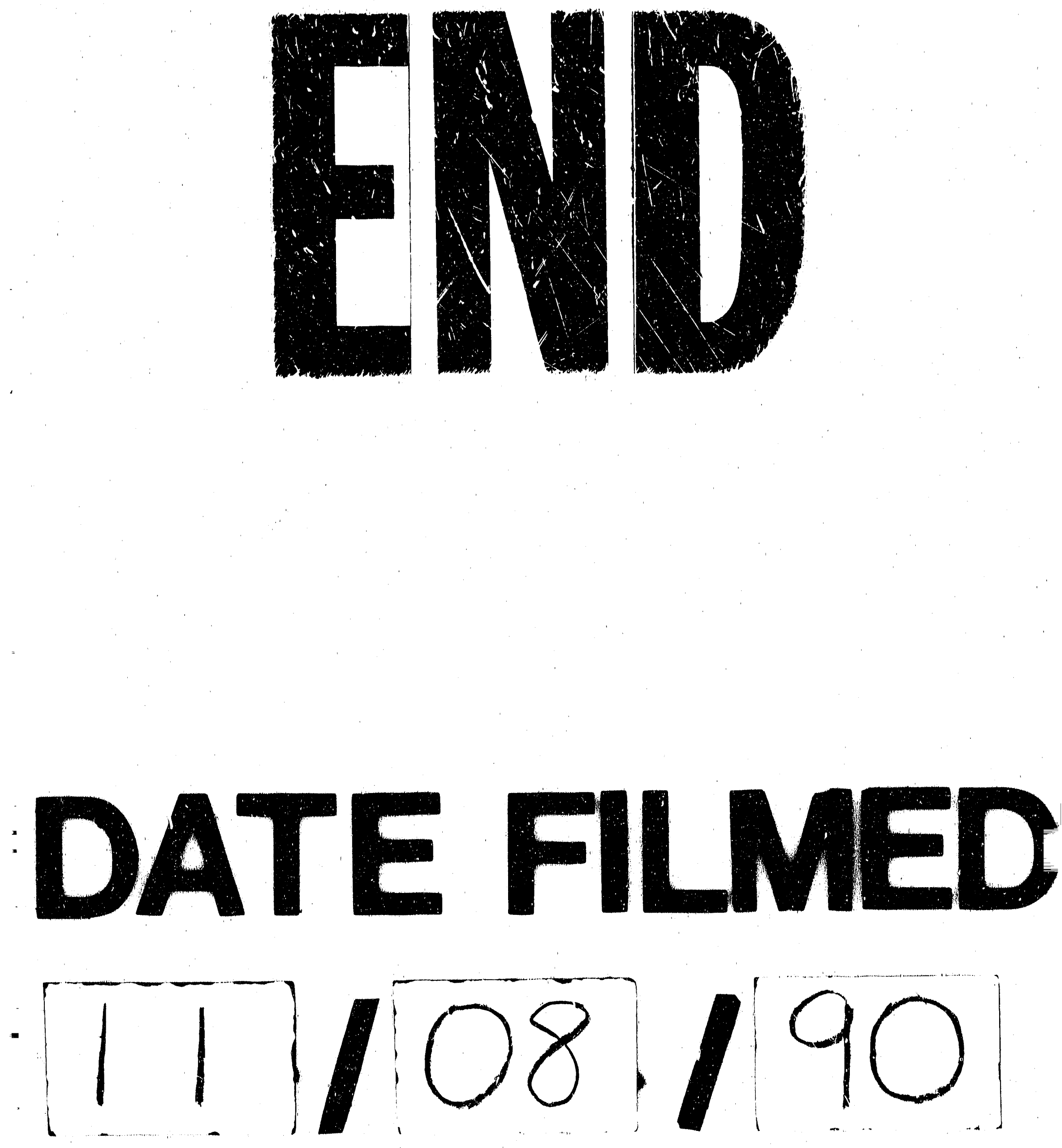
